\title{
8
}
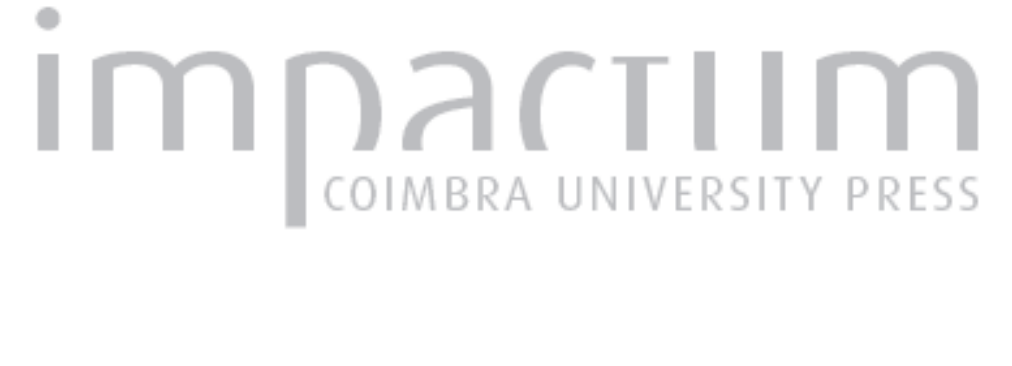

\section{O caminho de ferro e a construção da modernidade: uma geografia da memória da linha férrea Coimbra-Lousã}
Autor(es):
Carvalho, Paulo

Publicado por:

Faculdade de Letras da Universidade de Coimbra, Departamento de Geografia

URL

persistente:

URI:http://hdl.handle.net/10316.2/30187

DOI:

DOI:http://dx.doi.org/10.14195/0871-1623_32_4

Accessed : $\quad$ 26-Apr-2023 14:57:07

A navegação consulta e descarregamento dos títulos inseridos nas Bibliotecas Digitais UC Digitalis, UC Pombalina e UC Impactum, pressupõem a aceitação plena e sem reservas dos Termos e Condições de Uso destas Bibliotecas Digitais, disponíveis em https://digitalis.uc.pt/pt-pt/termos.

Conforme exposto nos referidos Termos e Condições de Uso, o descarregamento de títulos de acesso restrito requer uma licença válida de autorização devendo o utilizador aceder ao(s) documento(s) a partir de um endereço de IP da instituição detentora da supramencionada licença.

Ao utilizador é apenas permitido o descarregamento para uso pessoal, pelo que o emprego do(s) título(s) descarregado(s) para outro fim, designadamente comercial, carece de autorização do respetivo autor ou editor da obra.

Na medida em que todas as obras da UC Digitalis se encontram protegidas pelo Código do Direito de Autor e Direitos Conexos e demais legislação aplicável, toda a cópia, parcial ou total, deste documento, nos casos em que é legalmente admitida, deverá conter ou fazer-se acompanhar por este aviso.

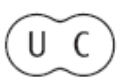




\section{O caminho de ferro e a construção da modernidade Uma geografia da memória da linha férrea Coimbra-Lousã}

\section{Paulo Carvalho}

Departamento de Geografia/Centro de Estudos de Geografia e Ordenamento do Território (CEGOT) Faculdade de Letras - Universidade de Coimbra paulo.carvalho@fl.uc.pt

\section{Nota preliminar}

0 presente texto decorre da conferência que proferimos no Auditório da Biblioteca Municipal da Lousã, a 24 de Fevereiro de 2007, no âmbito das atividades culturais programadas a propósito da "Comemoração do Centenário da Linha de Comboio Coimbra-Lousã (1906-2006)".

A nossa intervenção foi estruturada segundo três preocupações centrais, a saber: contextualizar a renovação das infraestruturas viárias e a modernização da Lousã; caracterizar a dinâmica territorial do contexto geográfico da linha de caminho de ferro CoimbraLousã(-Arganil, embora este seja apenas um lugar virtual na geografia do transporte ferroviário em Portugal), nomeadamente a urbanização e o planeamento urbano da Lousã, assim como a evolução demográfica e a estrutura do povoamento desta sub-região; relacionar o caminho de ferro e o processo de construção e projeção da imagem turística da Lousã e da sua Serra.

Entretanto, nestes cinco anos, a Linha da Lousã conheceu novos e importantes episódios. O Estado, cerca de uma década e meia após ter criado a empresa Metro Mondego (e de outro tanto período de indecisão em matéria de modelo e soluções para gerir o transporte ferroviário Coimbra-Serpins), tomou a decisão de implementar o projeto do Metro Mondego, que pretende modernizar a Linha da Lousã e criar um circuito novo na cidade de Coimbra (entre o Arnado e o novo Hospital Pediátrico, com passagem na Universidade), a que está associado um investimento público superior a quatrocentos milhões de euros. 0 início da intervenção na plataforma ferroviária aconteceu no final de 2009 e até ao momento estão concluídos os trabalhos de renovação da referida plataforma entre Serpins-Miranda do Corvo e Miranda do Corvo-Alto de São João (mas ainda sem a colocação de carris e catenária). A suspensão de diversas empreitadas subsequentes, o adiamento sucessivo dos prazos de conclusão das obras e a indecisão/ indefinição do Estado em relação a questões estruturais que carecem de uma resposta objetiva e urgente, é apenas uma face deste processo polémico, que hoje é uma incógnita e motivo de profunda preocupação nomeadamente da parte dos utentes e de quem defende os seus interesses, e será objeto de uma análise aprofundada da nossa parte em momento oportuno.

De forma prévia e sintética, importa clarificar, na perspetiva de uma abordagem geográfica, os principais traços da modernidade, designadamente: a compressão do espaço e do tempo; a interligação e a interdependência dos lugares e das sociedades; o crescimento exponencial do fenómeno urbano; a crescente dissociação lugar de residência/lugar de trabalho, e a afirmação da sociedade de consumo e de lazer.

Os transportes e as comunicações configuram relevantes ferramentas operativas da construção e consolidação deste processo.

Ao mesmo tempo, é oportuno caracterizar, em traços gerais, o quadro territorial em análise. $\mathrm{Na}$ óptica geomorfológica, trata-se de uma sub-região heterogénea, constituída por quatro subunidades morfoestruturais diferenciadas que marcam de forma muito vigorosa a paisagem. A sul, eleva-se de forma brusca o Maciço Antigo, com as Serras da Lousã (1205 metros), Caveiras (1005 metros) e São Pedro de Açor (1438 metros). São as balizas do bloco noroeste da Cordilheira Central Portuguesa (que culmina na Serra da Estrela). O sector intermédio corresponde à Bacia Sedimentar de Miranda do Corvo-Lousã-Góis-Arganil, com os seus «(...) depósitos relativamente finos, de origem granítica, anteriores ao levantamento das montanhas actuais (...)», e os «(...) depósitos grosseiros, derramados no sopé das vertentes de xisto e alimentados por ela, correlativos dos movimentos tectónicos que deram origem ao essencial do relevo da Cordilheira Central» (FerreIRA, 2005: 98). No seu interior e bordadura encontram-se diversas formas de relevo, como, por exemplo, a bacia topográfica da Lousã (onde se desenvolve a vila homónima), as colinas sedimentares (Areal e Alto do Padrão), os terraços fluviais (Cume e Chã do Freixo), a Serra de Sacões (com os seus depósitos grosseiros de material heterométrico, de natureza estrutural e litológica diferente da Serra da Lousã) e o canhão fluvial da Senhora da Candosa (rasgado pelo rio Ceira no alinhamento quartzítico do Buçaco 
aos Penedos de Góis. A noroeste é evidente o rebordo montanhoso do Maciço Antigo, com a designação local de Maciço Marginal de Coimbra (com uma forma geométrica aproximadamente triangular), subunidade percetível quando percorremos a Estrada da Beira (E.N. 17) desde a saída de Coimbra até às imediações de Foz de Arouce. Entre o rebordo montanhoso do Maciço Antigo e a Orla Mesocenozóica Ocidental, encontra-se a chamada Depressão Periférica. Esta última subunidade é muito visível, por exemplo, no sector Penela-Coimbra, em particular ao longo da E.N. 342 e da E.N. 110, no percurso Lamas-Marco dos Pereiros.

A esta diversidade estrutural corresponde uma marcada heterogeneidade litológica, dominada pela matriz metamórfica e sedimentar: xistos e grauvaques (Serra da Lousã e Rebordo Montanhoso), quartzitos (Penedos de Góis, em jeito de baliza oriental da Serra da Lousã), calcários, dolomias e margas (na Depressão Periférica), areias, argilas e arenitos, em especial na Bacia da Lousã. Estes últimos podem aparecer muito meteorizados, como acontece nas colinas sedimentares, ou pelo contrário, surgem envolvidos por uma matriz siliciosa que thes confere uma enorme dureza, como sucede com os grés de Alveite, baptizados com o vernáculo "pedra vermelha de Alveite", outrora utilizada nos trabalhos de cantaria para adornar portas e janelas assim como o fabrico de mós destinadas aos moinhos de água locais e de outras regiões do país (por exemplo, a área do Grande Porto). A título de exceção, assinalamos igualmente a presença de granitóides (Coentral e Vila Nova), embora pouco expressivos.

Após esta breve nota introdutória, avançamos para a temática central da nossa reflexão, designadamente enfatizando o primeiro eixo de análise: a modernização das infraestruturas viárias em Portugal e os seus efeitos regionais e locais.

\section{Renovação viária e modernização do território}

O caminho de ferro é uma das faces de maior visibilidade do processo de construção de uma nova geografia dos transportes em Portugal, desde meados do século XIX.

O conhecimento da organização dos transportes e das comunicações no nosso país, desde meados de Setecentos até ao início do século $\mathrm{XX}$, torna incontornável a referência às dissertações de doutoramento de Artur Teodoro de Matos (1980) e Maria Fernanda Alegria (1990). Estes importantes trabalhos de investigação reconhecem a influência negativa dos acidentes orográficos no que concerne ao traçado das vias e a sua penetração no interior do País, como acontece na área da Cordilheira Central.

A rede ferroviária nacional conheceu, na transição dos séculos XIX-XX, uma fase de relançamento, e pela primeira vez, os traçados das linhas férreas são orientados para o espaço interno com o intuito de servir preferencialmente os interesses locais e regionais, contrariamente ao período anterior, em que grande parte das diretrizes foram desenhadas sob influência de objetivos supranacionais (AlegriA, op. cit.).

Para a Lousã, o caminho de ferro é um importante factor de renovação e reposicionamento do município no novo mapa viário do país. Como escrevemos anteriormente, o lançamento das modernas infraestruturas viárias, primeiro as estradas reais e distritais, e depois o caminho de ferro, marca uma nova era no desenvolvimento da Lousã (CARVAlho, 1999). Desde logo, emerge uma questão que parece inevitável: como eram as comunicações na Lousã antes da modernização viária (meados do século XIX)?

Pelo menos até meados de Oitocentos a Lousã estava muito isolada e mal servida de vias de comunicação. Não obstante, é possível identificar algumas artérias do quadro viário local e regional, designadamente:

A Estrada Real de Lisboa a Almeida, que atravessava as colinas sedimentares a ocidente da vila; esta via passava no Corvo, Padrão, Arneiro, Senhora do Desterro (Espinheiro), Foz de Arouce, Poiares e daí avançava para a Beira Alta.

- A Estrada Coimbra-Guarda, antecessora da moderna Estrada da Beira; o percurso antigo fazia-se pelas cumeadas da Serra do Carvalho (Maciço Marginal de Coimbra).

A Estrada Coimbrã; partia do Fundo de Vila, atravessava a bacia topográfica da Lousã (Fonte dos Mouros, Senhora das Barraquinhas, Fontaínhas) e o rio Arouce (Ponte Coimbrã), cruzava a Estrada Real Lisboa-Almeida na área da Senhora do Desterro e seguia em direção ao Senhor da Serra e Coimbra.

A Estrada Velha da Serra, através dos Soutos de Cacilhas, para alcançar a Catraia, os Coentrais e a Ribeira de Pera; foi por este caminho, com traçado e condições de circulação muito difíceis, que passou parte significativa da maquinaria que permitiu a modernização industrial de Castanheira de Pera na segunda metade do século XIX. 
A partir de 1860 , e até ao início do século XX, o município da Lousã assistiu a uma progressiva renovação das suas vias de comunicação. A nova geografia dos transportes local e regional decorre da Estrada Real $n^{\circ}$ 12 (Coimbra-Celorico da Beira), Estrada Real n ${ }^{\circ} 52$ (de Coimbra a Castelo Branco, ou melhor, da Foz de Covelos a Castelo Branco, uma vez que o traçado de Coimbra até à Foz de Covelos coincide com a Estrada Real $n^{\circ} 12$ ), Estrada Distrital $n^{\circ} 66$ (Estrada Nova da Serra), Estrada Distrital $n^{\circ} 57$ (Soure-Condeixa-Miranda do Corvo-LousãGóis-Arganil-Tábua) e o caminho de ferro de Coimbra a Arganil (concretizado até Serpins, no termo oriental do município da Lousã). As novas vias cruzaram a malha urbana da Lousã e induziram novas direções para o crescimento e consolidação da vila (CARVALHO, 1999).

$\mathrm{O}$ atraso na construção de algumas vias, nomeadamente a Estrada da Serra, comprometeu em definitivo as aspirações da Lousã no que concerne às relações comerciais com a Ribeira de Pera. A lentidão do avanço desta via (iniciada no final dos anos 70 ou início de 80 e apenas concluída em 1929), tal como aconteceu com o projeto viário lançado desde o Espinhal (que demorou quase um século a concluir) explica, em larga medida, a aproximação do empório industrial de Castanheira de Pera em relação à Linha do Norte (estação de Pombal) e às vias de comunicação do Centro Litoral.

Importa explicar que durante muitos anos, a Ribeira de Pera foi uma prioridade nas ambições e projetos de desenvolvimento da Lousã. A vila da Lousã configurava um lugar de passagem e um entreposto para as mercadorias (matérias-primas e produtos acabados) relacionadas com a indústria têxtil de lanifícios de Castanheira de Pera. Em meados de Oitocentos, Castanheira de Pera conheceu uma fase de intenso crescimento e modernização industrial (PIRES, 1986), facto que coincide com o início do processo nacional de modernização das vias de comunicação. A Lousã entendeu a dimensão das mutações em curso e sentiu que não podia perder essa oportunidade estratégica.

Contudo, a renovação viária é um processo (político) muito complexo e dominado por enormes incertezas. Quantos projetos e cenários que colocavam a Lousã nesse corredor de passagem da montanha para o litoral não foram idealizados? 0 exemplo do caminho de ferro é, de igual modo, muito paradigmático. A linha de comboio Coimbra-Arganil aparece referenciada, de forma recorrente, em diversos projetos que faziam supor a sua continuidade para a Beira Alta, para a Beira Baixa (o centro polarizador do interesse, nomeadamente para a cidade de Coimbra, era a Covilhã, em face do seu dinamismo industrial) e até em direção a Tomar (CARVALHo,
1999). Temos para nós que esta situação gerou grandes expectativas (embora nunca concretizadas) ao concessionário da Linha de Arganil, numa época em que a geografia das ferrovias portuguesas estava em construção e era marcada por grande indefinição.

A ligação ao sector meridional da montanha era tão importante que, em vésperas da inauguração do caminho de ferro, no troço Coimbra-Lousã (16 de dezembro de 1906), alguns artigos na imprensa local, questionam a utilidade da ferrovia perante a incapacidade de concluir a Estrada da Serra, e perspetivam na nova via de articulação da montanha uma alternativa para aqueles que se dedicavam aos transportes antes da chegada do caminho de ferro.

Também a cidade de Coimbra acalentava expetativas positivas em relação ao caminho de ferro. Diversos episódios relegaram a cidade para um plano secundário no contexto nacional da moderna viação, nomeadamente o desvio (do entroncamento) da Linha da Beira Alta para a Pampilhosa do Botão, e o fracasso dos projetos de ligação de Coimbra à Beira Interior, em especial à cidade da Covilhã (a "Manchester Portuguesa", como era designada nessa época) e a Tomar (via Miranda do Corvo ou Lousã). Mesmo a edificação da estação da Linha do Norte, muito afastada do centro da cidade, mereceu abertas críticas na imprensa regional, como aconteceu com o Conimbricense, muito comprometido e preocupado com o desenvolvimento da cidade e da sua região.

Em meados dos anos 90 , por ocasião da nossa dissertação de mestrado, a respeito da génese, evolução e contextualização regional e nacional do caminho de ferro Coimbra-Arganil, identificámos alguns sinais desta indefinição como é o caso da localização da estação ferroviária da Lousã. O tempo longo de construção da ferrovia e a incerteza do seu traçado urbano arrastou a (in)decisão de localização da estação. Os cenários que a imprensa da época relata e que alguns documentos coevos apoiam (embora carecendo de confirmação em suportes cartográficos), sugerem duas situações que podem ter funcionado em alternativa ao local escolhido de forma definitiva para instalar a estação da Lousã. Um cenário, no alinhamento do traçado que hoje conhecemos, apontava a localização da estação em subvila, próximo da actual Rua Industrial Manuel Carvalho, entre a vila da Lousã, o Casal dos Rios e a Cruz de Ferro (na altura os principais lugares do termo do espaço urbano lousanense). Esta proposta, a concretizar-se, induziria a abertura de uma nova artéria de ligação ao coração da vila oitocentista: a Praça do Município, então muito apertada no sector (ocidental) de contacto 
com a Rua Viscondessa do Espinhal. A configuração moderna da Praça data dos anos 70 do século XX, quando foi concluída a renovação deste espaço (que teve a sua primeira grande operação de requalificação urbana no último terço do século XIX, quando se edificou a nova Matriz). Outro cenário, relacionado com um hipotético traçado da ferrovia entre a vila e a Serra, em condições técnicas muito difíceis (que obrigaria a construir um túnel no Alto das Tapadas), sugere a localização da estação no Regueiro (onde começa a Estrada Nova da Serra). A concretizar-se este último projeto, o traçado urbano do caminho de ferro ficaria mais próximo da fábrica de papel do Penedo, a maior interessada e com mais influência direta neste empreendimento (CARVALHO, 1996).

Apesar de todas as dificuldades, a Lousã ganhou uma nova posição relativa no mapa renovado das vias de comunicação. Ao mesmo tempo, a diretriz das novas artérias abriu interessantes perspetivas para a génese de frentes de urbanização.

\section{Dinâmica territorial do sector Coimbra-Lousã- -Arganil}

3.1 Efeitos urbanísticos do caminho de ferro na Lousã: o incremento da urbanização e as primeiras preocupações no contexto do planeamento urbano

Na vila da Lousã são os terrenos junto da estação e ao longo da (nova) avenida da estação (Fotografia 1) que despertam maior interesse e recebem, na transição do século, algumas obras particulares (CARVALHo, 1996).

$\mathrm{O}$ incremento da urbanização desencadeou preocupações urbanísticas, nomeadamente o alinhamento dos espaços construídos e a necessidade de estudar e

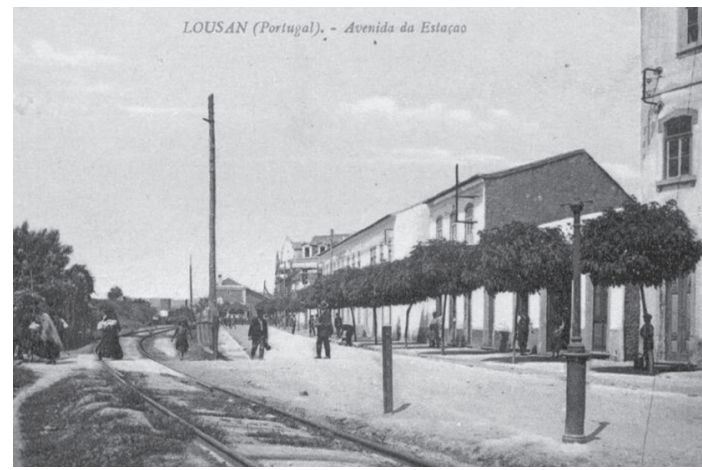

Fotografia 1

Avenida da Estação (Lousã), nos primeiros lustros do século XX. Fonte: Arquivo Histórico Municipal da Lousã planear novos arruamentos. Nessa época, em Portugal, não existia um verdadeiro quadro normativo de planeamento urbano. Aliás, o planeamento urbano com caráter sistemático e nacional teve início apenas na década de trinta.

A expectativa de crescimento da urbanização, relacionada com a inauguração do caminho de ferro, exigia o levantamento urgente de uma planta geral da vila e arredores. Esta tese é apoiada em dois extratos documentais coevos.

O jornal "O Lousanense", na edição n²44, de 9 de Março de 1905, refere a necessidade de levantar, através de uma planta, as «(...) novas ruas que neles devem ser abertas de futuro, a fim de que as edificações dos particulares vão sendo desde já dispostas com regularidade e segundo um plano geral (...)» (CARVALHO, 1999: 241).

Por sua vez, a Ata da Sessão Camarária de 23 de Março de 1905 (duas semanas após a notícia publicada em "O Lousanense") revela uma proposta no mesmo sentido, embora mais ambiciosa (com uma visão mais estratégica): «(...) que da mesma forma seja nela [planta] traçado o plano de novas ruas nos terrenos situados entre a estação do caminho de ferro e a vila atual, a nascente da estrada de Coimbra e da rua do Comércio, ruas a cuja abertura a Câmara se habilitará oportunamente» (CARValho, 1999: 242). Esta proposta, da autoria do vice-presidente Francisco Baeta Pires Serra, reflete o sentimento de subtrair a vila do espartilho setecentis ta e construir novos arruamentos para permitir a expansão planeada da vila para áreas mais desafogadas.

Em síntese, sentia-se a falta de uma planta de conjunto, com a vila e os seus arredores, tarefa que seria executada por Álvaro Viana de Lemos, em 1905, a partir de diversas plantas parcelares existentes na Direção Geral de Obras Públicas e na Companhia do Caminho de Ferro do Mondego (CARvalho, 1999). Esta planta surge na sequência de um outro exercício cartográfico realizado pelo autor, em 1898, com preciosas anotações sobre os equipamentos e os serviços públicos da Lousã.

Durante alguns anos a "Planta da Lousã e Casal dos Rios" (1905) - figura 1 - constituiu uma base cartográfica fundamental (e única) para responder a alguns problemas relacionados com a expansão urbana da Lousã (CARVAlho, 2004).

Nesta matéria, importa destacar também o "Plano de Melhoramentos para a Vila da Lousã" (1918) - figura 2 -, do arquiteto bracarense João de Moura Coutinho, documento elaborado a pedido da Câmara Municipal da Lousã. Trata-se de uma memória descritiva apoiada em planta urbana, com directrizes para a urbanização das 


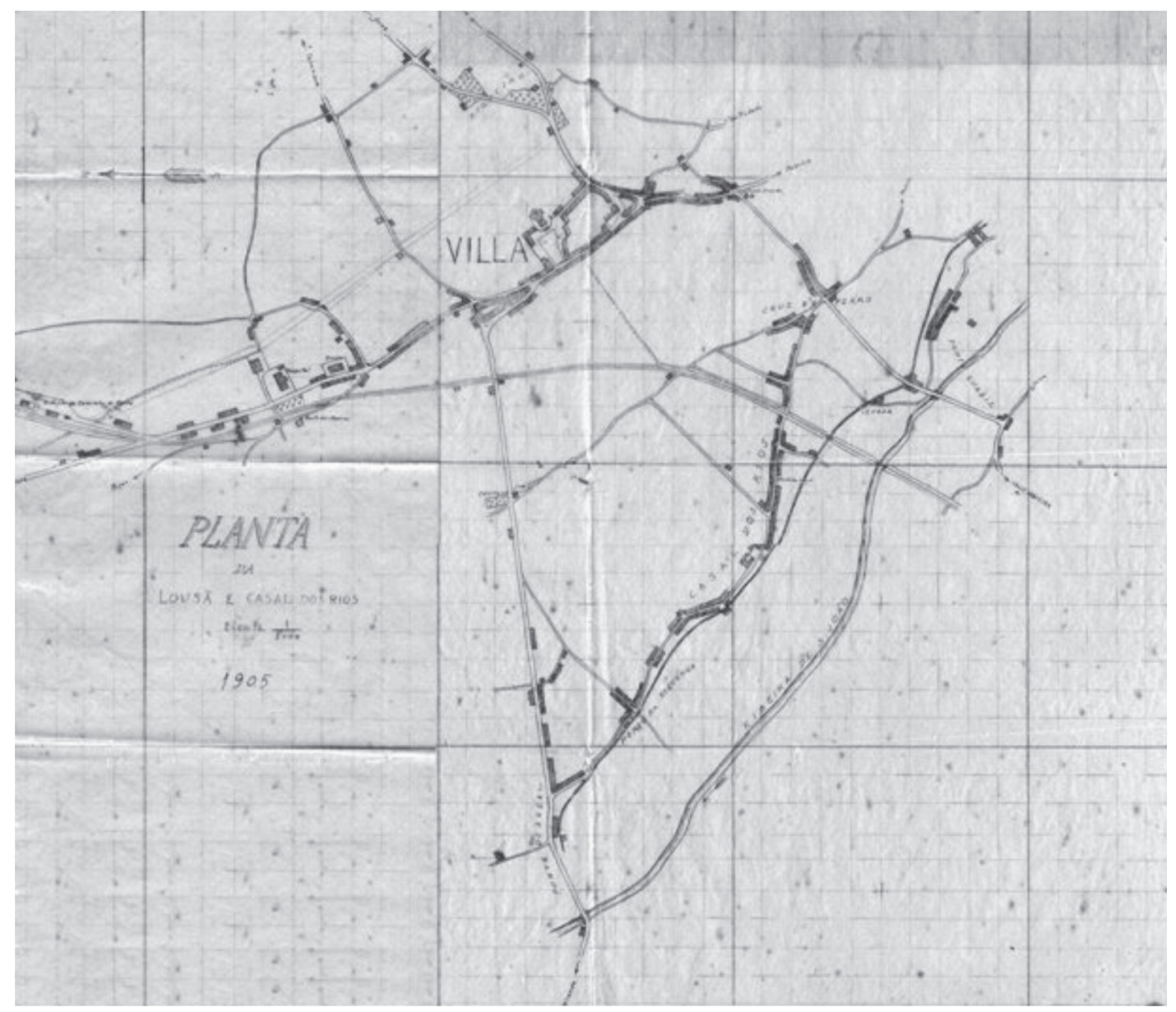

Figura 1

Planta da Lousã e Casal dos Rios (1905), desenhada por Álvaro Viana de Lemos.

Fonte: Arquivo Histórico Municipal da Lousã

Quintas, que por sua vez configura o primeiro loteamento urbano da Lousã (1916). Este documento, de caráter inovador (CARVALHO, 2004), orientou a expansão oriental da vila com importantes indicações para o desenho de novos arruamentos: Avenida Nova (Avenida Coelho da Gama) e artérias transversais (Ruas Dr. João Santos e Sacadura Cabral) e o alargamento da Travessa da Vaqueira. Moura Coutinho defende, também, o alargamento da Praça do Município, projeto iniciado mais tarde e concluído na segunda metade dos anos 70 , fixando o desenho urbano e a imagem que hoje conhecemos. Na ideia de Moura Coutinho, esta realização era prioritária para a Lousã e sem a sua concretização estaria comprometida a expansão urbana da vila. No Plano de Melhoramentos é feita referência ao prolongamento da Nova Avenida. Embora sem indicação do rumo, é de admitir a influência da estação do caminho de ferro e a visão de um eixo novo que libertaria a vila da malha viária antiga com todos os constrangimentos nomeadamente a circulação de veículos, ambição concretizada na década de 30 com a abertura da Avenida do Brasil.

Hoje, percorrendo as artérias urbanas ou espreitando a partir da magnífica varanda de Gevim, é quase intuitivo encontrar os traços que retratam as principais fases da evolução urbana da vila da Lousã. Nota-se a vila antiga, até 1865 (que configura uma versão realista e sedimentada do centro histórico); o prolongamento setentrional da malha urbana relacionado em primeiro com a renovação das vias de transporte, nomeadamente o caminho de ferro; a expansão oriental da vila com as avenidas novas; o crescimento a poente do caminho de ferro, em particular desde o início dos anos 90 .

Um século após a chegada do caminho de ferro, com tanta influência no traçado da malha urbana da Lousã, a estação e a sua envolvente, são espaços a requalificar no âmbito de dois importantes projetos: 


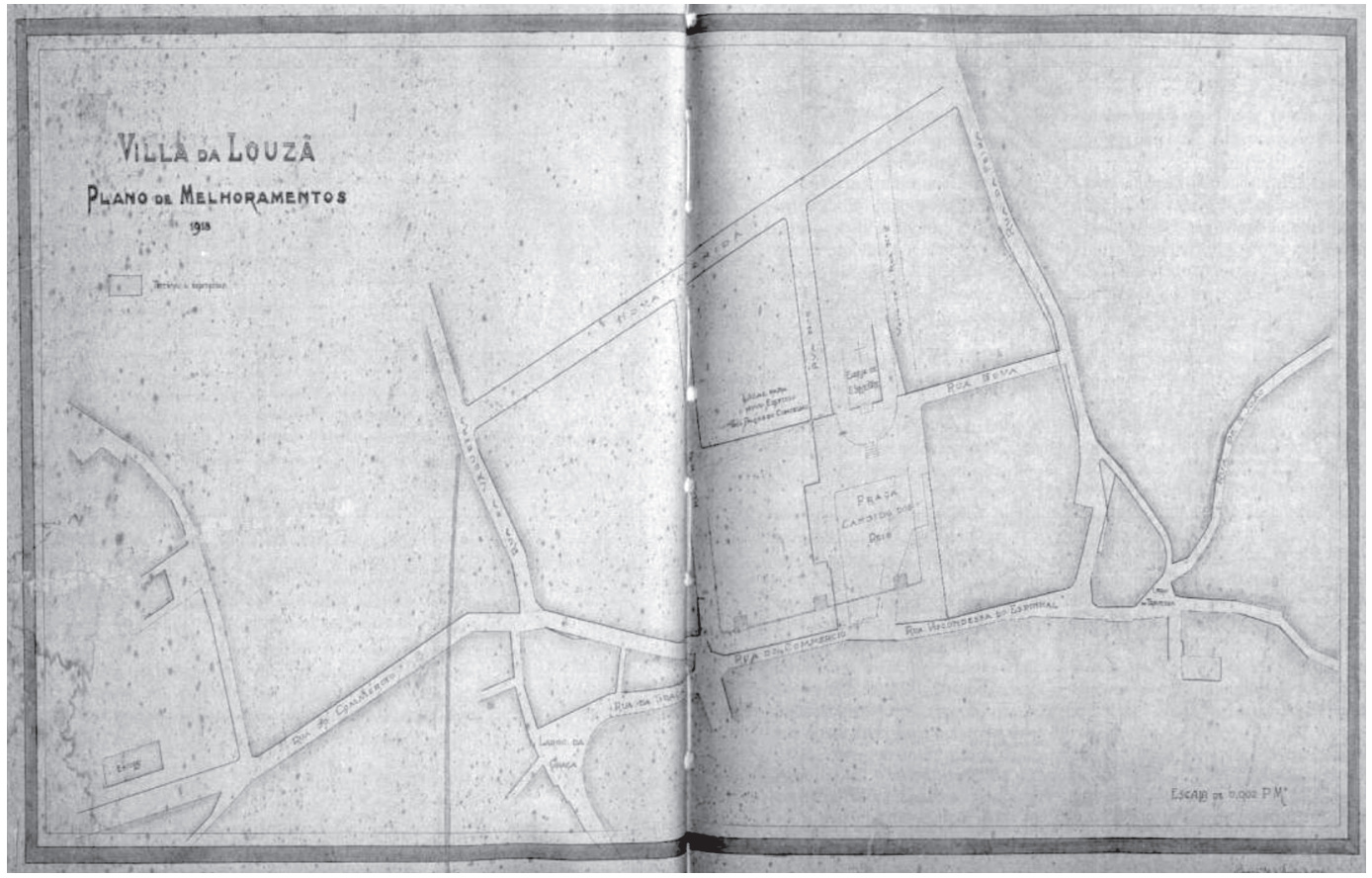

Figura 2

Planta da Vila da Lousã (1918), de João de Moura Coutinho

Fonte: Arquivo Histórico Municipal da Lousã

por um lado, a construção de um novo corredor setentrional, uma avenida do e para o século XXI, a ligar a Avenida do Brasil e as rotundas que articulam com as variantes (E.N. 342 e E.N. 236) a meio da antiga Reta do Freixo; por outro lado, a modernização da Linha da Lousã, com implicações em todo o corredor/canal do caminho de ferro, designadamente a reconversão e a requalificação das estações e antigas estruturas e equipamentos que perderam funcionalidade. Admitindo a necessidade de construir uma nova plataforma logística de embarque de passageiros, e o facto de a estação estar em rota de colisão com a nova avenida setentrional, é pertinente salvaguardar o edifício (e alguns elementos simbólicos relacionados com o caminho de ferro como, por exemplo, a grua do antigo cais de mercadorias), com a possibilidade deste assumir novas funções, como é preocupação do município. Perante um cenário de nova funcionalidade, seria interessante integrar no velho edifício (mais) alguns elementos da memória do caminho de ferro, seja uma sala para exposição de painéis temáticos com documentos e imagens históricas, seja o aproveitamento de alguns vãos de parede para a mesma finalidade. Esta preocupação não colide com a intenção de instalar alguns serviços públicos de grande interesse para os utentes. Aliás, é oportuno recordar que um dos maiores problemas de conservação do pa- trimónio é a ausência de função e o encerramento dos edifícios. Devolver o património aos cidadãos e utilizar o património em estratégias planeadas de mediação social, segundo diversas perspectivas de educação patrimonial, é um processo de valorização do património e um grande desafio do nosso tempo.

No alinhamento destes objetivos é relevante a possibilidade de utilizar um conjunto de vias paralelas ao caminho de ferro, pelo menos ao longo do traçado da Linha no município da Lousã, e articular com outros caminhos antigos, para criar circuitos pedestres e ciclovias, acompanhados de sinalização adequada, leitores de paisagem e folhetos explicativos e de divulgação.

Tudo isto sem esquecer a questão central: a modernização da linha de comboio Coimbra-Lousã (como dever e compromisso do Estado em relação aos territórios e às populações) e a sua afirmação como símbolo do transporte (sub)urbano moderno e sustentável.

\subsection{População e povoamento}

O segundo eixo de análise, na perspetiva das trajetórias de desenvolvimento do contexto territorial da linha de comboio Coimbra-Lousã, sugere a apresentação, de forma resumida, de um conjunto de elementos estatísticos sobre a evolução da população e o povoamento. 
O Quadro I reflecte a evolução demográfica no período 1890-2004 e inclui também os municípios do sector meridional da Serra da Lousã. A leitura interpretativa da informação estatística permite fixar algumas conclusões. Assim, no intervalo de tempo 1890-2001, verificamos um crescimento significativo da população no sector Coimbra-Arganil. O saldo positivo de 89.753 habitantes corresponde a um acréscimo de $84.7 \%$ em relação ao final do século XIX. A leitura da mesma variável para o sector meridional da Serra da Lousã, revela uma dinâmica muito diferenciada. Os dados estatísticos indicam um saldo negativo de quase 13.000 habitantes, o que significa, para o período em análise, uma redução de $45.4 \%$ da população. Contudo, no sector Coimbra-Arganil registam-se também fortes assimetrias internas. Vamos considerar as situações extremas: o município de Coimbra quase triplicou a população residente em 1890-2001; pelo contrário, o concelho de Góis perdeu mais de metade da sua população em igual período (-55\%). Lousã (+47.3\%) e Arganil (-35.2\%) apontam no mesmo sentido, embora com menor intensidade.

As últimas estimativas demográficas do Instituto Nacional de Estatística confirmam estas tendências (Quadro I). A manter-se o ritmo, em poucos anos, o município da Lousã terá sensivelmente a mesma população residente que o conjunto dos municípios de Góis, Figueiró dos Vinhos, Castanheira de Pera e Pedrógão Grande. As diferenças de população no final do século XIX e nas primeiras décadas do século XX eram pouco significativas, sem considerar a individualização administrativa de Castanheira de Pera (em relação a Pedrógão Grande) - que ocorreu em 1914. A partir dessa época, os concelhos serranos (e de um modo geral o interior português) não conseguiram evitar uma desvitalização social e económica progressiva, muito acentuada no período 1940-1981, que causou enormes perdas demográficas e o envelhecimento acelerado da população residente, comprometendo a renovação das gerações e a sobrevivência de muitos lugares.

Com efeito, o desequilíbrio entre os grupos etários principais, nomeadamente jovens e idosos, está muito marcado nos concelhos serranos, em especial no período 1991-2001 (CARVAlho, 2005). Em 2001, o número de idosos é praticamente o triplo da população jovem nos concelhos de Pedrógão Grande (278.7\%) e Góis (268.1\%), e quase duas vezes mais em Castanheira de Pera (194.7\%), Figueiró dos Vinhos (188.8\%) e Arganil (188.2\%). Lousã (108.3\%), Miranda do Corvo (113.0\%) e Coimbra (119.6\%) apresentam um índice de envelhecimento mais próximo da média nacional (102\%) e ligeiramente abaixo da média regional (129.6\%).

A estrutura demográfica é marcada também por um desequilíbrio na composição da população por sexo, consequência da mobilidade espacial, interna (em especial Lisboa) e externa (das Américas aos países da Europa Ocidental), que envolveu a população ativa mais jovem. "Nos últimos anos, este facto decorre, em larga medida, da mobilidade local que exerce um efeito drenante nas áreas rurais a favor, regra geral, dos lugares mais importantes (sedes) dos municípios. Deste modo, se explica, igualmente, uma certa recomposição interna do povoamento" (CARVALHo, 2005: 269).

Contudo, a dimensão local dos processos de despovoamento é ainda mais expressiva no quadro da montanha. As freguesias de Coentral (Castanheira de Pera), Campelo (Figueiró dos Vinhos) e Espinhal (Penela), no período 1911-2001, perderam 73 a $82 \%$ da população (Carvalho, 2005). Alvares (Góis) e Vila Nova (Miranda do Corvo), em igual período, sofreram também uma quebra demográfica muito expressiva: -77 e -46\% da população, respetivamente. Com efeito, os registos estatísticos confirmam a existência de freguesias que perdem efectivos populacionais desde o início do século $X X$. O último registo censitário (2001) permite identificar

Quadro I

Evolução da população da área Coimbra-Serra da Lousã, em 1890-2004, por concelho

\begin{tabular}{|c|c|c|c|c|c|c|c|c|c|c|}
\hline Concelhos & 1890 & 1911 & 1930 & 1940 & 1950 & 1960 & 1981 & 1991 & 2001 & 2004 \\
\hline Arganil & 21037 & 21151 & 20691 & 22002 & 21736 & 19237 & 15507 & 13926 & 13623 & 13187 \\
\hline Coimbra & 51226 & 62423 & 77439 & 85702 & 98027 & 106404 & 138930 & 139052 & 148443 & 142408 \\
\hline Góis & 10797 & 12466 & 12421 & 12448 & 11103 & 9744 & 6434 & 5372 & 4861 & 4606 \\
\hline Lousã & 10692 & 12358 & 13375 & 14525 & 15442 & 13900 & 13020 & 13447 & 15753 & 17252 \\
\hline Miranda do Corvo & 12244 & 12859 & 12691 & 13558 & 13822 & 12810 & 12231 & 11674 & 13069 & 13400 \\
\hline Total & 105996 & 121257 & 136617 & 148235 & 160130 & 162095 & 186122 & 183471 & 195749 & 190853 \\
\hline Castanheira de Pera & - & (5 608) & 5971 & 6411 & 6330 & 5739 & 5137 & 4442 & 3733 & 3464 \\
\hline Figueiró dos Vinhos & 15152 & 10201 & 11067 & 12031 & 12300 & 11545 & 8754 & 8012 & 7352 & 7080 \\
\hline Pedrógão Grande & 13170 & 13477 & 9062 & 9250 & 8955 & 8239 & 5842 & 4643 & 4398 & 4262 \\
\hline Total & 28322 & 23678 & 26100 & 27692 & 27585 & 25523 & 19733 & 17097 & 15483 & 14806 \\
\hline
\end{tabular}

Fontes: Censos e Recenseamentos da População, Lisboa, INE, 1890-2001. Anuário Estatístico da Região Centro (2004), Lisboa, INE, 2005. 
freguesias com menos de 200-250 habitantes: Coentral (Castanheira de Pera), com 154; Colmeal (Góis), com 229 habitantes; Cepos, Anceriz, Teixeira, Moura da Serra e Piódão (Arganil), com 174, 188, 188, 168 e 224 habitantes, respetivamente.

Ao mesmo tempo, a estrutura do povoamento reflecte grandes assimetrias. A leitura da repartição da população segundo a dimensão dos lugares, a partir dos Censos 2001, com base nos elementos recolhidos e tratados na nossa dissertação de doutoramento (CARVALho, 2005) permite concluir acerca da preponderância dos pequenos lugares sobretudo nos municípios de matriz serrana. Em Pedrógão Grande, Figueiró dos Vinhos, Castanheira de Pera e Góis, cerca de 2/3 ou mais da população vive em lugares com menos de 200 habitantes, sendo que nestes concelhos mais de metade da população reside em lugares com menos de 100 habitantes (excepto Castanheira Pera, onde essa classe representa $36 \%$ ). Pelo contrário, na Lousã apenas $27.6 \%$ da população vive em lugares com menos de 200 habitantes e em Miranda do Corvo esse registo é de $42.2 \%$.

A dimensão demográfica dos lugares é outro elemento que reflecte dinâmicas sócio-territoriais amplamente diferenciadas (CARVALHo, 2005). Ainda a partir dos Censos 2001 é possível hierarquizar os lugares segundo a população residente: Coimbra (101.108 habitantes); Lousã (6.941 habitantes); Miranda do Corvo (2.811 habitantes); Arganil (2.677 habitantes); Figueiró dos Vinhos (1.597 habitantes); Castanheira de Pera (1.164 habitantes); Pedrógão Grande (1.011 habitantes) e Góis (884 habitantes). A importância relativa da sede de concelho no total demográfico de cada município é igualmente assimétrica: Coimbra (68.1\%); Lousã (44.1\%); Castanheira de Pera (31.2\%); Pedrógão Grande (23\%); Figueiró dos Vinhos (21.7\%); Miranda do Corvo (21.5\%); Arganil (19.7\%); Góis (18.2\%).

A mobilidade da população, em particular os trabalhadores, é importante também para compreender a capacidade de atração ou repulsão dos municípios no plano da oferta de emprego.

A partir da informação estatística (disponível mas não publicada) sobre a população empregada residente nos concelhos de Arganil, Góis, Lousã e Miranda do Corvo, a exercer actividade em outros municípios, em 1991-2001, podemos concluir que a capacidade local de oferta de emprego na Lousã é superior em relação a Miranda do Corvo. Em 1991, 19.5\% da população empregada exercia actividade em outro concelho; no caso de Miranda do Corvo essa taxa era de $46.4 \%$ (o valor mais elevado do conjunto dos municípios do Pinhal Interior Norte e Baixo Mondego). Uma década depois, a Lousã passa para um registo de $32.9 \%$ e Miranda do Corvo atinge $51 \%$ (valor apenas superado em Condeixaa-Nova, com 54.2\%, e Soure, com 51.7\%). Góis e Arganil apresentam menor mobilidade da população empregada: $11.7 \%$ e $8.3 \%$, em $1991 ; 18.2 \%$ e $13.6 \%$, em 2001 , respectivamente (CARVALHo, 2005).

De igual modo, é possível conhecer a dependência destes municípios em relação a Coimbra, o centro de gravidade da maior bacia de emprego regional. A maior dependência é de Miranda do Corvo (83.1\% em 1991; 75.5, em 2001), tal como acontece com os municípios de Condeixa-a-Nova (77.7\%, em 1991; 70.4\%, em 2001), Penacova (70.1\%, em 1991; 65.7\%, em 2001) e Vila Nova de Poiares (64.3\%, em 1991; 55.2\%, em 2001). O município da Lousã reforçou ligeiramente a sua dependência face a Coimbra no plano do emprego: 51.4\% em 1991; 57.1\%, em 2001 (CARVAlho, 2005).

Por outro lado, os fluxos de mão de obra entre os municípios da Serra da Lousã são pouco significativos, tal como acontece entre o Pinhal Interior Norte e o Pinhal Interior Sul. Em 1991, as deslocações da Lousã para Castanheira de Pera, Figueiró dos Vinhos e Pedrógão Grande envolveram 8 trabalhadores $(0.8 \%)$ e em relação a Miranda do Corvo tratava-se de 6 trabalhadores (0.3\%). Do sector meridional da Serra, com destino aos concelhos de Lousã e Miranda do Corvo, partiram apenas 3 trabalhadores. De facto, os movimentos pendulares refletem as relações mais próximas entre os municípios de cada um dos sectores da montanha: Penela, Miranda do Corvo, Lousã, Góis, e Figueiró dos Vinhos, Castanheira de Pêra, Pedrógão Grande (CARVALHo, 2005).

No período 1991-2001 pouco mudou: as deslocações da Lousã e de Miranda do Corvo para o sector meridional da Serra representam 0.5 e $0.3 \%$, respectivamente, valor que sobe para $1.9 \%$ em relação aos movimentos pendulares com origem em Penela, e para quase $11 \%$ no caso de Góis. Nos concelhos da vertente meridional da Serra, os resultados de 2001 permitem constatar a diminuição da importância de Figueiró dos Vinhos e de Castanheira de Pera como destino dos trabalhadores residentes em Pedrógão Grande (de 2/3 para 1/3 das deslocações diárias); a perda da importância relativa das deslocações de Figueiró dos Vinhos para Ansião, e o reforço de Castanheira de Pera, Pedrógão Grande, Leiria, Sertã; o aumento da percentagem de trabalhadores com origem em Castanheira de Pêra e com destino aos municípios de Figueiró dos Vinhos, Pombal, Ansião e Alvaiázere, facto que está relacionado com a crise de emprego no concelho, sendo que os trabalhadores continuam a privilegiar o sector secundário (Carvalho, 2005: 285). 
4. O caminho de ferro como alavanca para a construção e projeção de imagens e espaços turísticos

O derradeiro eixo desta reflexão remete para uma temática de grande interesse e importância estratégica: o turismo "alternativo" e a afirmação de lugares como a Lousã no mapa da nova oferta turística em Portugal. O caminho de ferro foi um pretexto para a Lousã marcar uma posição no quadro emergente do turismo em Portugal. Assinalamos este facto, inovador, e circunscrevemos a análise ao essencial deste acontecimento, abrindo caminho a uma leitura mais aprofundada (no seguimento da abordagem que iniciámos na nossa dissertação de doutoramento).

$\mathrm{Na}$ origem do processo de construção e divulgação da imagem turística da Lousã e da Serra da Lousã destacam-se os contributos da ciência, pintura, literatura e jornalismo, desde meados do século XIX (CARVALHO, 2005).

As primeiras notícias publicadas resultam de viagens e expedições científicas, por vezes integradas em roteiros regionais e nacionais. Sobretudo Adrião Forjaz de Sampaio (1838), com a primeira viagem de índole turística e cultural à Lousã, mas também Alexandre Herculano (1853), J. Rivoli e Bernardino de Barros Gomes (1873), Júlio Henriques (1887), entre outros, deixaram importantes registos sobre a Serra da Lousã. Sabemos hoje que o interior da montanha foi o grande motivo de interesse dos viajantes e que a elite da vila da Lousã teve um papel muito relevante na receção e apoio logístico aos visitantes. De um modo geral estes relatos mostram o aspeto desolador da Serra, associado ao processo de desarborização e aos intensos efeitos erosivos.

Contudo, a propaganda turística da Lousã e da Serra da Lousã teve o seu decisivo impulso com o folheto "O Viajante na Lousã"1 (figura 3), publicado por ocasião da inauguração da linha de comboio CoimbraLousã (16 de Dezembro de 1906), através do jornal "O Louzanense" ( $\left.n^{\circ} .331\right)$. O autor, Álvaro Viana de Lemos ${ }^{2}$ (1881-1972), iniciava, assim, uma colaboração longa, dedicada e profícua, com o município da Lousã, em de-

${ }^{1}$ Uma segunda edição desta publicação (que se encontrava esgotada), aumentada com ilustrações, plantas e cartas foi impressa em 1913 recebendo o título "Roteiro Ilustrado do Viajante na Lousã". A receita reverteu a favor da construção de uma casa para a Escola de Cova do Lobo (Lousã).

${ }^{2}$ Sobre a vida e a obra ímpar desta figura relevante com grande expressão nos domínios da docência (pioneiro do movimento da Educação Nova em Portugal), das artes plásticas e da propaganda turística, veja-se a Arunce (revista de divulgação cultural do município da Lousã), $n^{\circ} 3 / 4$, de 1990, que reúne um conjunto significativo de contribuições no âmbito de uma justíssima homenagem, a título póstumo, promovida pela Câmara Municipal da Lousã.
Inanğuracăo do Caminho de Perro de Coimbra á Lousâ.

\section{O \\ Viajante na Lousã}

\author{
ereng \\ Aspectos geracs \\ Yl Lousã antiga \\ C. Gastello \\ Fls ermidas de $\mathcal{S}$. Fua e $\mathcal{S}_{r}{ }^{\mathrm{a}}$ da Picdade \\ A Frabricu do P. cnedo \\ A Serra \\ Qasscios e pontos de vista
}

nare

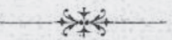

1906

Figura 3

Capa do folheto "O Viajante na Lousã" (1906), de Álvaro Viana de Lemos Fonte: Arquivo Histórico Municipal da Lousã

fesa e propaganda da cultura e turismo da Lousã e da sua Serra.

Este folheto assume o objetivo de divulgar as paisagens da Lousã e informar os visitantes sobre os motivos de interesse e os meios de alojamento. Citando Lemos (1906: 4), a "(...) excecional situação e belezas naturais [da Lousã] dão-lhe porém, desde logo, direito de ambicionar um lugar entre os pontos obrigatórios da visita ao excursionista estrangeiro. (...) Assim como o estrangeiro que passa por Lisboa não deixa de ir a Sintra ou Cascais, assim o que passar por Coimbra não deixará um dia de visitar o Buçaco e a Lousã”.

As sugestões de visita recomendam a vila antiga (com as suas casas brasonadas) e sobretudo os passeios e pontos de vista, aos arredores da vila e à Serra. Este facto reflete uma importante mutação no discurso e na imagem da montanha que se consolida nas décadas seguintes. Com efeito, a Serra, até então sinónimo de paisagens desoladoras, feias e hostis, começa a ser interpretada como um recurso para afirmar a Lousã no universo emergente do turismo, designadamente o turismo interno. Esta vertente turística assumirá alguma relevância alguns anos mais tarde, no âmbito da estratégia do Secretariado Nacional de Informação, Cultura 
Popular e Turismo, uma vez que este representava uma procura mais regular, estável e difusa pelo território (CAvaco, 2005). A arborização pelos Serviços Florestais, a conclusão da Estrada da Serra (Lousã - Castanheira de Pera) e o seu embelezamento com espécies arbóreas, a construção de mirantes e pequenas áreas de lazer, e a abertura de caminhos e ramais de ligação aos lugares serranos e pontos de interesse turístico, estão entre os fatores que contribuíram para tornar mais acessivel e aliciante a descoberta e fruição da Serra da Lousã.

\section{Referências Bibliográficas}

AlegriA, Maria Fernanda (1990) - A organização dos transportes em Portugal (1850-1910). As vias e o tráfego. Memórias do C.E.G. $n^{\circ} 12$, Lisboa, Universidade de Lisboa/I.N.I.C., $560 \mathrm{p}$.

Carvalho, Paulo (1996) - A Vila da Lousã. Contributo para um Estudo de Geografia Urbana. Dissertação de mestrado em Geografia Humana apresentada à FLUC, Coimbra, 435 p. (trabalho publicado em 1999 pela Câmara Municipal da Lousã).

CarvalHo, Paulo (2004) - "Planeamento urbano: entre projectos e realizações. O exemplo do Plano de Melhoramentos da Vila da Lousã (1918). Arunce. Revista de Divulgação Cultural, n. ${ }^{\circ} 17-18,2002 / 2004$, Lousã, C.M.L., pp. 3-18.

Carvalho, Paulo (2005) - Património cultural e trajectórias de desenvolvimento em áreas de montanha. O exemplo da Serra da Lousã. Dissertação de doutoramento em Geografia apresentada à FLUC, Coimbra, 657 p.

Cavaco, Carminda (2005) - "Os Espaços de Turismo". In Medeiros, Carlos Alberto (dir. e coord.) - Geografia de Portugal. Actividades Económicas e Espaço Geográfico. Lisboa, Círculo de Leitores, pp. 408-422.

Ferreira, António de Brum (2005) - "Formas de Relevo e Dinâmica Geomorfológica”. In MedeIRos, Carlos Alberto (dir.) Geografia de Portugal. O Ambiente Físico. Lisboa, Círculo de Leitores, pp. 53-255.

Lemos, Álvaro Viana de (1906) - O Viajante na Lousã. Lousã, Tipografia Lousanense, $15 \mathrm{p}$.

Lemos, Álvaro Viana de (1913) - Roteiro Ilustrado do Viajante na Lousã. Lousã, Tipografia Lousanense, 31 p. $\left(2^{a}\right.$ edição).

MATOS, Artur Teodoro de (1980) - Transportes e Comunicações em Portugal (1750-1850). Ponta Delgada, 650 p.

PIRES, Iva (1986) - "Génese e evolução de um centro produtor têxtil. A indústria de lanifícios em Castanheira de Pêra". Finisterra, 21(42), Lisboa, CEG, pp. 271-309. 